\title{
IDENTIFICAÇÃO DE UM NOVO FOCO DE ESQUISTOSSOMOSE MANSONI. (MUNICÍPIO DE NOVA LIMA, MG, BRASIL)
}

\author{
Henrique Leonardo Guerra, Carlos Tito Guimarães, \\ Marco Antônio T. França, Roberto Sena Rocha e Naftale Katz
}

\begin{abstract}
É relatada a deteç̧ão de um novo foco de transmissão da esquistossomose mansoni, no município de Nova Lima (região metropolitana de Belo Horizonte, MG, Brasil). Na localidade conhecida por Banqueta do Bananal, no bairro da Boa Vista, foram capturados 356 exemplares de Biomphalaria glabrata dos quais $30(8,4 \%)$ estavam infectados. Dos 162 moradores submetidos ao exame de fezes, 91 eliminavam ovos de Schistosoma mansoni, apresentando uma prevalência de 56,0\%. A ação conjunta dos moradores e da Prefeitura Municipal levou à eliminação do foco, sendo esta uma solução poucas vezes conseguida em situações semelhantes.
\end{abstract}

Palavras-chaves: Esquistossomose mansoni. Prevalência. Biomphalaria glabrata

Informações anteriores sobre a ocorrência de esquistossomose mansoni na população residente em Nova Lima ${ }^{4}$ mostravamprevalências baixas, $0,1 \%$ em 1950 e 1,0 em 1978 indicando, provavelmente, a não ocorrência de infecção autóctone nesta área.

Em julho de 1988 o encontro casual de exemplares de Biomphalaria glabrata na localidade conhecida por Banqueta do Bananal, no bairro da Boa Vista no município de Nova Lima, MG, levou aos estudos aqui relatados que demonstram a existência de um importante foco de transmissão da esquistossomose ${ }^{2}$.

\section{MATERIAL E MÉTODOS}

O município de Nova Lima está situado na região metalúrgica de Minas Gerais distante cerca de $22 \mathrm{~km}$ da capital, Belo Horizonte, estando ligado à mesma por estrada de rodagem asfaltada e da qual está geograficamente separado pela Serra do Curral. Segundo estimativas do

Superintendência de Campanhas de Saúde Pública, MG. Centro de Pesquisas René Rachou - FIOCRUZ, MG Bolsista de Iniciação Científica do CNPq.

Endereço para correspondência: Dr. Henrique L. Guerra, Av. Augusto de Lima 1715, 30190 Belo Horizonte, MG. Recebido para publicação em 16/05/91
Ministério da Saúde, o município teria em 1988 cerca de 47000 habitantes dos quais $91,0 \%$ na zona urbana?.

A localidade denominada Banqueta do Bananal fica situada na parte alta da cidade sendo considerada um anexo do bairro Boa Vista. A chamada Banqueta é um corte na encosta do morro por onde, em uma vala $(1,00 \times 0,30 \mathrm{~m}$ de largura $e$ profundidade respectivamente), corria a água vinda de uma lagoa distante cerca de $8 \mathrm{~km}$ do local. Ao longo desta Banqueta, a população de 179 habitantes está distribuída em 35 casas de alvenaria. A distância entre a primeira e a última casa é de aproximadamente $3 \mathrm{Km}$.

Em agosto de 1988 a Companhia de Saneamento de Minas Gerais (COPASA/MG) passou a fornecer água tratada à todas as casas. Até então os moradores serviam-se da água da vala para todos os fins. Ainda assim, algumas famulias continuaram a fazer uso da água da vala enquanto esta esteve disponivel.

A partir da constatação da presença de moluscos hospedeiros intermediários do Schistosoma mansoni foram realizadas, na vala, três capturas pelo sistema de conchadas ( 1 conchada/metro linear) em seis estações de pesquisa. Concomitantemente, foram realizados exames coproscópicos, pelo método de Kato-Katz ${ }^{3}$ em 162 $(90,5 \%)$ dos 179 moradores desta área, sendo 77 homens, 85 mulheres. 
Guerra HL, Guimarães CT, França MAT, Rocha RS, Katz N. Identificação de um novo foco de esquistossomose mansoni. (Municipio de Nova Lima, MG, Brasil). Revista da Sociedade Brasileira de Medicina Tropical 24:169-172, jul-set, 1991

Em novembro de 1988 os pacientes positivos para esquistossomose foram tratados com oxamniquine (Mansil ${ }^{R}$ ) na dose única oral de $15 \mathrm{mg} / \mathrm{kg}$ de peso para os adultos e de $20 \mathrm{mg} / \mathrm{kg}$ para as crianças (menos de 15 anos). Por outro lado, a população da Banqueta foi orientada para, juntamente com a Prefeitura Municipal, tomar providências no sentido da eliminação do criadouro de planorbídeos.

\section{RESULTADOS}

Foram coletados 356 exemplares de Biomphalaria glabrata. Destes, $30(8,4 \%)$ estavam infectados pelo $S$. mansoni. Dos 162 moradores examinados, através do exame de fezes, $91(56,2 \%)$ apresentavam ovos de $S$. mansoni nas fezes (Tabela 1), sendo que $36(40,0 \%)$ indivíduos tinham até 99 ovos por grama de fezes (opg), $41(45,0 \%)$ tinham entre 100 e 499 opg e $14(15,0 \%)$ apresentavam mais de 500 opg. A mediana de distribuição do número de ovos por grama de fezes foi de $120 \mathrm{e} \mathrm{a}$ média geométrica de 141,2 opg. O indice de infecção foi de $61 \%$ entre os homens e de $53 \%$ entre as mulheres, porém esta diferença não foi estatisticamente significativa (Qui-quadrado = $0,66, p=0,42)$. Também não houve diferença no índice de infecção entre as faixas etárias (Quiquadrado $=7,60, \mathrm{p}=0,37$ ) ficando acima de $45,0 \%$ em todos os grupos etários.

Foram examinados clinicamente 99 indivíduos dos quais $57(62,0 \%)$ estavam eliminando ovos de $S$. mansoni. Destes últimos, todos foram classificados como forma instestinal.

Dos 91 pacientes tratados em novembro de $1988,73(80,0 \%)$ foram reexaminados através de um exame de fezes pelo método de Kato-Katz em junho de 1989. Destes pacientes 19 tinham ovos de $S$. mansoni nas fezes determinando-se, por este critério, um índice de cura de 74,0\%.

Entre os pacientes não curados houve uma redução, estatisticamente significativa, pelo teste de Análise da Variância $(\mathrm{p}<0,05)$, do número de ovos por grama de fezes após o tratamento. Estes 19 pacientes tinham média geométrica de 246,9 opg antes do tratamento, passando a apresentar a média geométrica de 64,6 opg após o tratamento.

Tabela 1 - População examinada, percentagem de infecção, mediana e média geométrica do número d' ovos por grama de fezes.

\begin{tabular}{ccccc}
\hline $\begin{array}{c}\text { Faixa } \\
\text { etária }\end{array}$ & $\begin{array}{c}\text { Número de } \\
\text { examinados }\end{array}$ & $\begin{array}{c}\text { Percentagem } \\
\text { de infeç̧ão }\end{array}$ & Mediana & $\begin{array}{c}\text { Média } \\
\text { geométrica }\end{array}$ \\
\hline $0-4$ & 11 & 45 & 36 & 53,7 \\
$5-9$ & 14 & 50 & 182 & 218,8 \\
$10-14$ & 13 & 46 & 366 & 316,2 \\
$15-19$ & 20 & 80 & 187 & 162,2 \\
$20-24$ & 23 & 52 & 143 & 186,2 \\
$25-34$ & 26 & 65 & 155 & 182,0 \\
$35-54$ & 31 & 55 & 107 & 91,2 \\
$>=55$ & 24 & 48 & 112 & 83,2 \\
\hline Total & 162 & 56 & 120 & 141,2 \\
\hline
\end{tabular}


Guerra HL, Guimarães CT, França MAT, Rocha RS, Katz N. Identificação de un novo foco de esquistossomose mansoni. (Municipio de Nova Lima, MG, Brasil). Revista da Sociedade Brasileira de Medicina Tropical 24:169-172, jul-set, 1991

Das ações empreendidas pela comunidade local, em conjunto com a Prefeitura, resultou a realização das obras necessárias ao aterramento da Banqueta e consequente eliminação do criadouro de planorbídeos responsável pela transmissão da parasitose.

\section{DISCUSSÃO}

Em dois levantamentos anteriormente realizados no município de Nova $\operatorname{Lima}^{48}$, ambos utilizando amostras da população de escolares (7 a 14 anos), foram constatadas prevalências de infecção esquistossomótica bastante baixas, $0.1 \%$ e $1.0 \%$, em 1950 e 1978 , respectivamente. Tais taxas sugeriram a não ocorrência de transmissão autóctone da doença à época da realização dos levantamentos.

A população estudada na Banqueta do Bananal em 1988, caracterizou-se por apresentar altos índices de infeç̧ão, acima de $45,0 \%$, em todas as idades, porém com cargas parasitárias baixas, provavelmente responsáveis pela forma intestinal encontrada em todos os 57 casos examinados clinicamente.

Com o encontro, na localidade, de planorbídeos infectados pelo S. mansoni, verificouse que estavam estabelecidas as condições para a transmissão autóctone da doença. Por outro lado os registros de dispensação de medicamentos indicam que, provavelmente, a transmissão não está restrita àquela localidade, devendo ser encontrada também em outras áreas do mesmo município.

Quanto ao tratamento com oxamniquine os resultados foram os esperados 5 . Tendo como critério de cura o resultado negativo em um exame de fezes pelo método de Kato-Katz, realizado sete meses após o tratamento, $74,0 \%$ dos pacientes foram considerados curados. Entre os pacientes não curados o tratamento reduziu significamente a carga parasitária estimada pela média geométrica do número de ovos por grama de fezes.

Os fatos aqui apresentados parecem estar de acordo com outros estudos realizados em Minas Gerais ${ }^{16}$ que demonstram a expansão da esquistossomose mansoni em algumas áreas do estado.
A ação conjunta das entidades comunitárias e Prefeitura Municipal resultou na éliminação física do foco de transmissão, constituindo um tipo de solução poucas vezes possível em situações semelhantes. Estudos posteriores, poderão verificar a eficácia das medidas. Fica em aberto a verificação da ocorrência de transmissão da esquistossomose no restante do município.

\section{SUMMARY}

The detection of a new transmission focus of schistosomiasis in Nova Lima town, Minas Gerais State, Brazil, is reported. The search of snail intermediate hosts in Banqueta do Bananal a small locality of Boa Vista neighbourhood detecled 356 specimes of Biomphalaria glabrata, with a infection rate of $8.4 \%$. In hundred-sixty-two patients stool examinations (KatoKatz method) were done, showing ninety-one patients with eggs of Schistosoma mansoni in their fees. The integrated action of local residents and the local administration resulted in the elimination of the focus.

Key-words: Schistosomiasis mansoni. Prevalence. Biomphalaria glabrata.

\section{REFERÊNCIAS BIBLIOGRÁFICAS}

1. Carvalho OS, Rocha RS, Massara CL, Katz N. Primeiros casos autóctones de esquistossomose mansoni $\mathrm{em}$ região do noroeste do Estado de Minas Gerais (Brasil). Revista de Saúde Pública 22: 237-239, 1988

2. Guerra HL, Guimarães CT, França MAT, KatzN. Identificação de um novo foco de esquistossomose no município de Nova Lima, MG - Brasil. In: Resumos do XXV Congresso da Sociedade Brasileira de Medicina Tropical, Florianópolis p.174, 1989

3. Katz N, Chaves A, Pellegrino J. A simple device for quantitative stool thick-smear technique in schistosomiasis mansoni. Revista do Instituto de Medicina Tropical de São Paulo 14: 397-400, 1972.

4. Katz N, Motta E, Oliveira VB, Carvalho EF. Prevalência da esquistossomose em escolares no Estado de Minas Gerais. In: Resumos do XIV Congresso da Sociedade Brasileira de Medicina Tropical, João Pessoa p.102, 1978.

5. Katz N, Rocha RS. Double-blind clinical trial comparing praziquantel with oxamniquine in 
Guerra HL, Guimarães CT, França MAT, Rocha RS, Katz N. Identificação de um novo foco de esquistossomase mansoni. (Município de Nova Lima, MG, Brasil). Revista da Sociedade Brasileira de Medicina Tropical 24:169-172, jul-set, 1991

schistosomiasis mansoni. Revista do Instituto de Medicina Tropical de São Paulo 24: 310-314, 1982.

6. Lambertucci JR, Rocha RS, Carvalho OS, Katz N. A esquistossomose mansoni em Minas Gerais. Revista da Sociedade Brasileira de Medicina Tropical 20: 47-52, 1987.
7. Ministério da Saúde. Estimativas de população. Subsistema de informação sobre população. Ministério da Saúde, Brasília, DF, 1987.

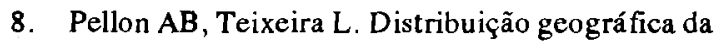
esquistossomose mansoni no Brasil. Divisão de Organização Sanitária, Ministério da Saúde, Rio de Janeiro, 1950. 